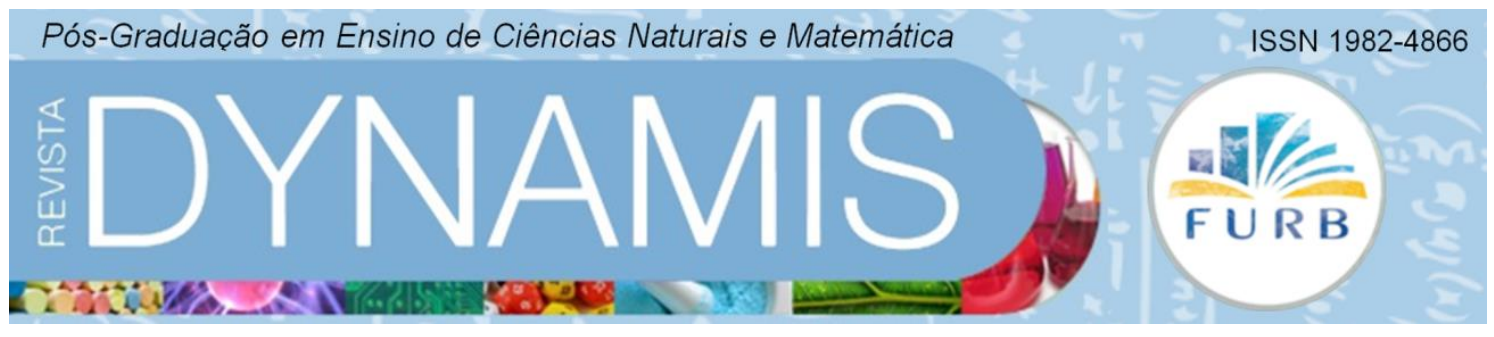

\title{
SOFTWARE GEOGEBRA PROPORCIONANDO O ENSINO DE FUNÇÕES TRIGONOMÉTRICAS NO ENSINO SUPERIOR
}

\author{
GEOGEBRA SOFTWARE PROVIDING THE TEACHING OF TRIGONOMETRIC \\ FUNCTIONS IN HIGHER EDUCATION
}

MSc. Romildo Pereira da Cruz Doutorando do Programa PPGEnsino Universidade do Vale do Taquari - UNIVATES

romildo.cruz@universo.univates.br

Dra. Marli Teresinha Quartieri

Coordenadora do Mestrado em Ensino de Ciências Exatas

Docente do Programa de Pós-graduação em Ensino

Professora do Centro de Ciências Exatas e Tecnológicas

Universidade do Vale do Taquari - UNIVATES

mtquartieri@univates.br

MSc. Andréia Spessatto De Maman

Doutoranda do Programa PPGEnsino

Universidade do Vale do Taquari - UNIVATES

Professora do CETEC - UNIVATES

andreiah2o@univates.br 


\title{
Resumo
}

O relato descrito remete-se a uma prática da disciplina de Estágio de Docência no Ensino Superior, na qual se desenvolveu um estudo de natureza qualitativa com 34 alunos dos cursos de Engenharia de Universidade do Interior do Rio Grande do Sul, na disciplina Introdução às Ciências Exatas. A proposta tendeu ao desenvolvimento de funções trigonométricas por meio de atividades e resolução de problemas que envolveram construção de gráficos usando o software GeoGebra. O instrumento da observação sistemática serviu de base para as nossas interpretações. Os resultados obtidos foram indicativos para concluir que o uso dessa estratégia contribui para a organização do ensino das funções; no entanto, é necessário possibilitar o acesso dos alunos às ferramentas necessárias. Constatou-se que a participação em tarefas que envolvem o uso de tecnologia e manipulação de materiais potencializa o aprendizado das funções. Porém, o simples uso da tecnologia não é suficiente para que a aprendizagem ocorra, pois a atuação do professor tem papel importante na mediação da construção do conhecimento dos seus alunos. Da mesma forma, observou-se que a interação entre alunos, e destes com o professor, é essencial para uma aprendizagem com mais significado.

Palavras-chave: Funções trigonométricas; GeoGebra; Introdução às Ciências Exatas.

\begin{abstract}
The described report refers to a practice of the subject of Teaching Internship in Higher Education, in which a qualitative study was developed with 34 students of the courses of Engineering of Interior University of Rio Grande do Sul in the subject of Introduction to Science Exact. The proposal tended to the development of trigonometric functions through activities and problem solving that involved the construction of graphs using GeoGebra software. The instrument of systematic observation served as the basis for our interpretations. The results obtained were indicative to conclude that the use of this strategy contributes to the organization of the teaching of the functions; however, it is necessary to allow students access to the necessary tools. It was verified that the participation in tasks that involve the use of technology and manipulation of materials enhances the learning of the functions. However, the simple use of technology is not sufficient for learning to occur, since the teacher's role plays an important role in mediating the construction of the knowledge of his students. In the same way, it was observed that the interaction between students, and these with the teacher are essential for a learning with more meaning.
\end{abstract}

Keywords: Trigonometric functions; GeoGebra; Introduction to Exact Sciences. 


\section{INTRODUÇÃO}

Bortoli, Marchi e Giongo (2016), ao abordarem o contexto Histórico do ensino da Trigonometria, salientam que o surgimento da Matemática ao longo da história evidenciou-se como uma manifestação cultural com o objetivo de solucionar os problemas impostos pela humanidade. Ainda segundo as autoras, esse processo fez surgir novas possibilidades de usabilidade da Matemática que desencadearam novas ramificações, dentre elas a Trigonometria. Também asseveram que essa ferramenta é um campo profícuo da Matemática e, por isso, está presente nos currículos do Ensino e em disciplinas básicas de alguns cursos superiores.

Em sua pesquisa, Silva e Frota (2010) explicitaram que a experiência acumulada de anos de prática em sala de aula permite compreenderem algumas dificuldades que alunos apresentam para aprender Trigonometria. Os autores destacam que, entre elas, esta à falta de conexão que os alunos percebem quanto à utilidade da trigonometria para além de situações escolares. Isso pode denotar a concepção generalizada de docentes de que poucos alunos do Ensino Médio ou Superior conseguem mobilizar seus conhecimentos para resolverem problemas práticos em situações posteriores ao que é trabalhado em sala de aula.

Ao se considerar os aspectos mencionados, é plausível pensar em recursos que possam diversificar os processos considerados tradicionais de abordagem do assunto. Isto posto, faz-se saber que uma das alternativas possíveis é o uso de aplicativos e de softwares, pois, acredita-se que a partir de diferentes estímulos e motivações seja possível que os alunos atinjam outros níveis de percepção, permitindo a relacionarem conceitos com suas abstrações.

Ao discutir as quatro fases das tecnologias digitais em Educação Matemática, Borba, Silva e Gadanidis (2015) enfatizam a forma como a sala de aula tem se transformado para incorporar ou impedir a entrada dessas tecnologias. Segundo os autores, vídeos, internet, Facebook, Geogebra, YouTube e GeogebraTube estão no topo do ranque e já são ferramentas consideradas naturais dentro do contexto educacional, pois, fazem parte da sala de aula, transformando-a e, por vezes, colocando em xeque a sua existência. Para os autores, o uso do computador como uma ferramenta didática pode tornar a aula mais dinâmica, pois insere o aluno nos processos de ensino e aprendizagem.

Faz-se saber que essas quatro fases comentadas pelos autores citados anteriormente estão relacionadas às mudanças que as tecnologias informáticas trouxeram para os ambientes de aprendizagem, desde a criação do laboratório de informática até a noção de mobilidade, proporcionada pela internet sem fio. Para Borba, Silva e Gadanidis (2015, p. 17), "as dimensões da inovação tecnológica permitem a exploração e o surgimento de cenários alternativos para a educação e, em especial, para o ensino de Matemática

Diante do exposto, tem-se que considerar a maneira acelerada com que as tecnologias vêm se estruturando. Segundo Borba, Silva e Gadanidis (2015), essa é uma característica que está marcando a atual sociedade. De acordo com os autores, de maneira cada vez mais extemporânea, "os computadores pessoais têm maior capacidade de processamento e memória, as interfaces ficam mais amigáveis e interativas e a conexão da internet mais veloz" (BORBA; SILVA; GADANIDIS, 2015, p. 17). Estes ainda salientam que, 
Além disso, surgem novos tipos de versões mais atualizadas de linguagens de programação, sistemas operacionais, softwares, aplicativos para internet, redes sociais e equipamentos eletrônicos multifuncionais portáteis, como notebooks, tablets, telefones celulares, câmeras digitais, dentre outros (Ibdem, 2015, p. 17).

Nesse percurso, os autores se perguntam se essas inovações se tornam acessíveis e se distribuem pela sociedade no mesmo ritmo. Para eles, mesmo não ocorrendo essa acessibilidade, as inovações permitem a exploração e surgimento de cenários novos.

Segundo Borba (1999b, apud KALINKE, 2014, p. 91), a incorporação de recursos tecnológicos em processos educacionais pode trazer benefícios, porém, acaba gerando, neles, interferências estruturais. De acordo com esse autor, devemos nos inspirar e acrescentar novas práticas possíveis na sala de aula de Matemática, observando que mais importantes do que apontar dificuldades é verificar as potencialidades. "Até hoje, também, ainda é discutido o que os alunos deixarão de saber se passarem a utilizar as novas tecnologias com frequência, ao invés de concentrar a atenção sobre o que eles passam a aprender se essas novas tecnologias se fizerem presentes" (BORBA, 1999b, p. 17).

Embora, por diferentes motivos, haja certa rejeição de utilização dos recursos das TIC pelos professores, o programa GeoGebra tem se configurado em uma exceção, pois tem boa aceitabilidade e bastante difundido por estes pares. Em linhas gerais, o software GeoGebra apresenta uma interface de fácil manipulação. Possui múltiplas funcionalidades, podendo ser utilizado em campos como: aritmética, álgebra, geometria, trigonometria. Esta última, em especial, caracteriza o foco da nossa abordagem. A intenção do uso do recurso propiciou explorar sua dinamicidade e algumas potencialidades do mesmo.

O GeoGebra recebeu esse nome pela possibilidade de operar com as representações aritmética, algébrica e geométrica conjuntamente. Isso significa que um objeto construído com o mouse ou digitando sua sintaxe na Entrada pode possuir mais de uma representação. [...] é um software com finalidades didáticas para ser utilizado em situações de ensino e aprendizagem de matemática (GEOGEBRA, 201-).

Em sua interface encontra-se uma Barra de Ferramentas localizada na parte superior, que é composta de 12 conjuntos de ícones com os recursos necessários para o usuário construir, movimentar, obter medidas e modificar atributos de objetos construídos, propiciando dinamismo nos processos de ensino e de aprendizagem.

Ademais, o software GeoGebra apresenta características voltadas para relacionar variáveis com números, vetores e pontos, permitindo, ainda, calcular derivadas e integrais de funções e oferece comandos, como raízes e extremos. De acordo com Borges Neto (200?), o software GeoGebra viabiliza a abordagem de assuntos simples e, através de suas ferramentas, há possibilidade de abordagens de conhecimentos mais complexos. Dada toda essa dinamicidade proporcionada pelo software, o elencamos como protagonista das ações que desencadearam a escrita deste artigo.

A intervenção pedagógica socializada neste artigo faz parte das atividades da disciplina Estágio de Docência no Ensino Superior de uma Universidade do Interior do Rio Grande do Sul. As práticas efetivadas aconteceram na turma de quarta-feira, na disciplina Introdução às Ciências Exatas, do turno noturno, da instituição supracitada, totalizando 12 encontros de 50 minutos cada. A referida turma era composta por 34 alunos na faixa etária entre 19 e 32 anos. Foi ofertada para alunos dos diversos cursos de Engenharia da Instituição, e as atividades 
desenvolvidas estiveram em consonância com orientações da professora titular da disciplina, respeitadas na sua integralidade pelo pesquisador. $\mathrm{O}$ trabalho teve o intuito de explorar inicialmente as relações do triângulo retângulo, com a construção do conceito de funções periódicas até a construção de gráficos de composições de funções trigonométricas, partindo das mais simples até as mais complexas, a exemplo: $y=\operatorname{sen}(x), z=\cos (x)$ e $\operatorname{tg}(x)$, com a função afim $w=a \cdot x+b$ onde $a$ e $b c \boldsymbol{R}$.

Também nos propusemos a construir gráficos para $f(x)=c \cdot \operatorname{sen}(a \cdot x+b)+d$ ou $\quad g(x)$ $=c \cdot \cos (a \cdot x+b)+d$, identificando a ideia de movimentos dos gráficos a partir das alterações de cada um dos quatro parâmetros utilizando recursos computacionais. Esse momento de construção fez-se necessário para o aluno experimentar, simulações no software que confirmassem os conceitos abordados. Salientamos que a construção de gráficos mais complexos ocorreu com o auxílio de gráficos parciais, também elaborados com uso do computador para cada parâmetro, sempre utilizando a ordem " $a$ ", " $b$ ", “c" e " $d$ " dos parâmetros.

Esta abordagem pretendeu estabelecer um contexto objetivo para a compreensão e construção do conceito de variações de parâmetros nestes tipos de gráficos, auxiliada pela experimentação feita pelos alunos durante a resolução dos exercícios. A proposta objetivou promover reflexões acerca do conteúdo, através da utilização de recursos menos usual, mas com uma linguagem adequada ao nível dos alunos da disciplina, com menos formalismo, mas sem abrir mão dos corretos e necessários conceitos físicos e matemáticos.

\section{DETALHAMENTO DAS ATIVIDADES}

A disciplina Introdução às Ciências Exatas contempla, na sua ementa, o aperfeiçoamento das diversas formas de descrever o comportamento de situações dinâmicas, seja na forma de texto técnico, gráfico, tabela, equação ou lei matemática. A fim de fundamentar a proposta, foram apresentados os seguintes objetivos:

Desenvolver a capacidade de compreender e descrever de múltiplas formas o comportamento de situações dinâmicas da natureza e das ciências;

Aperfeiçoar as diversas formas de descrever o comportamento de funções, seja na forma de texto, gráfico, tabela, equação ou lei;

$\checkmark \quad$ Desenvolver autonomia, por meio de atividades diversificadas, como: investigações práticas, problemas desafio e uso de tecnologias de comunicação e informação;

$\checkmark \quad$ Desenvolver nos alunos o gosto para pensar, lógica e matematicamente;

$\checkmark \quad$ Desenvolver a habilidade de resolver problemas teóricos e práticos relacionados à área científica;

$\checkmark \quad$ Desenvolver a capacidade de buscar informações complementares na bibliografia disponível e em meios virtuais.

No contexto em que foi pensada a disciplina, nossa intenção foi de averiguar se ocorriam significativas mudanças na maneira de os alunos interpretarem as funções, os problemas e os gráficos e, caso ocorressem, permitiria buscar explicações sobre as implicações que levaram a tal mudança, em que níveis elas ocorrem e de que maneira afeta os processos que estruturam o 
pensamento do aluno. Acredita-se que o uso sistemático do recurso possa desenvolver outros meios de aprendizagem.

O trabalho é justificado pelo eminente crescimento no ritmo de integração das mídias digitais no contexto de ensino, em particular, na Matemática tem se constituído em expoente, dando outros vieses aos processos de ensino e de aprendizagem. Acredita-se que, no estudo de funções, a simbologia utilizada do recurso computacional, adicionada à interface gráfica proporcionada por softwares, permite mudanças na compreensão do conteúdo de funções trigonométricas.

Assim, foram pensadas e elaboradas atividades que permitissem ao aluno, explorar, contextualizar, discutir e refletir sobre os processos de construção e de manipulação dos termos relacionados às dadas funções. Faz-se saber que foi necessária uma sequência de três aulas denominadas de aula 1, aula 2 e aula 3 - para desenvolver a construção completa do ciclo trigonométrico com o software e as atividades que serão relatadas a seguir. Cada aula teve a duração de três horas e trinta minutos.

O objetivo da primeira aula (aula 1) foi apresentar aos alunos as possibilidades de utilização do software Geogebra e verificar a sua aplicação no estudo das funções: seno, cosseno e tangente. Dessa maneira, procuramos socializar com os alunos o nosso conhecimento acerca das ferramentas do software.

Nesse momento, foi feita uma sondagem em relação a quanto os alunos conheciam o Geogebra. Isso evidenciou o ponto de partida para o início da abordagem. Destacou-se a importância da possibilidade da visualização, modelação e animação das construções, o que em nosso entendimento, pode favorecer a abstração do conteúdo por parte dos alunos. Foram feitas, ainda, indagações adaptadas (SURVIO, 2018) acerca da presença do software no contexto da disciplina.

$\checkmark$ Vocês já utilizaram um software de Matemática livre em suas aulas? conteúdo?

$\checkmark$ Vocês conhecem o software Geogebra? Já o utilizaram em algum

$\checkmark$ Vocês acreditam que a visualização do conteúdo pelo software Geogebra irá facilitar o aprendizado do conteúdo de funções trigonométricas mais do que em sala de aula, no quadro?

No tocante aos questionamentos, evidenciou-se que poucos alunos até então tinham feito uso do recurso Geogebra, seja durante o Ensino Médio ou no Ensino Superior. Ressalva-se que a disciplina relacionada com o assunto é obrigatória para diversos cursos da área das Engenharias, e que tínhamos alunos dos primeiros períodos de diferentes cursos. Tais alunos explicitaram que pouco ou quase nada tinham aprendido acerca do assunto em anos anteriores e que consideravam importante que os professores pudessem diversificar o uso de recursos para a abordagem do conteúdo, considerado complexo para eles.

Segundo Oliveira (2009a), o professor precisa entender que a amplitude de estratégia com o uso de softwares permite compreender melhor a visão que os alunos possuem acerca das chamadas tecnologias "tradicionais" (uso de sólidos, giz e lousa, lápis e papel, régua e compasso, etc). O processo de mescla das tecnologias informáticas com outras já utilizadas pelos professores, ao que nos parece, como outras abordagens igualmente válidas, podem, em dados momentos, apresentar maior pertinência, dependendo do cenário que se delineie em relação aos objetivos que se deseje atingir a partir do assunto abordado. 
Com vista a dar maior notoriedade à potencialidade do recurso escolhido para a abordagem, no seguimento da aula, apresentou-se o vídeo "Tutorial Geogebra - parte I" de 5 minutos e 42 segundos, disponível em http://www.youtube.com/, o qual evidencia as principais funcionalidades do software Geogebra. A utilização do recurso fez-se necessária vista que na sondagem inicial poucos haviam explicitado saberem lidar com as ferramentas do software. Após a apresentação, deu-se a distribuição e utilização do tutorial parte I de construção do ciclo trigonométrico (MAMAN; ZIEGLER; PRITSCH, 2014), que foi disponibilizado no ambiente virtual da disciplina para que os alunos pudessem tê-lo como ferramenta auxiliar as construções pretendidas, ou seja, para aqueles que não estavam tão seguros quanto ao manuseio do software, o tutorial serviu como um guia prático.

Neste percurso, ainda foi utilizado um projetor multimídia onde os alunos poderiam, através dos slides projetados (FIGURA 1), acompanhar o desenvolvimento da construção dos gráficos das funções cíclicas, a partir da circunferência trigonométrica de raio unitário.

FIGURA 1 - interface do software após construção do ciclo trigonométrico

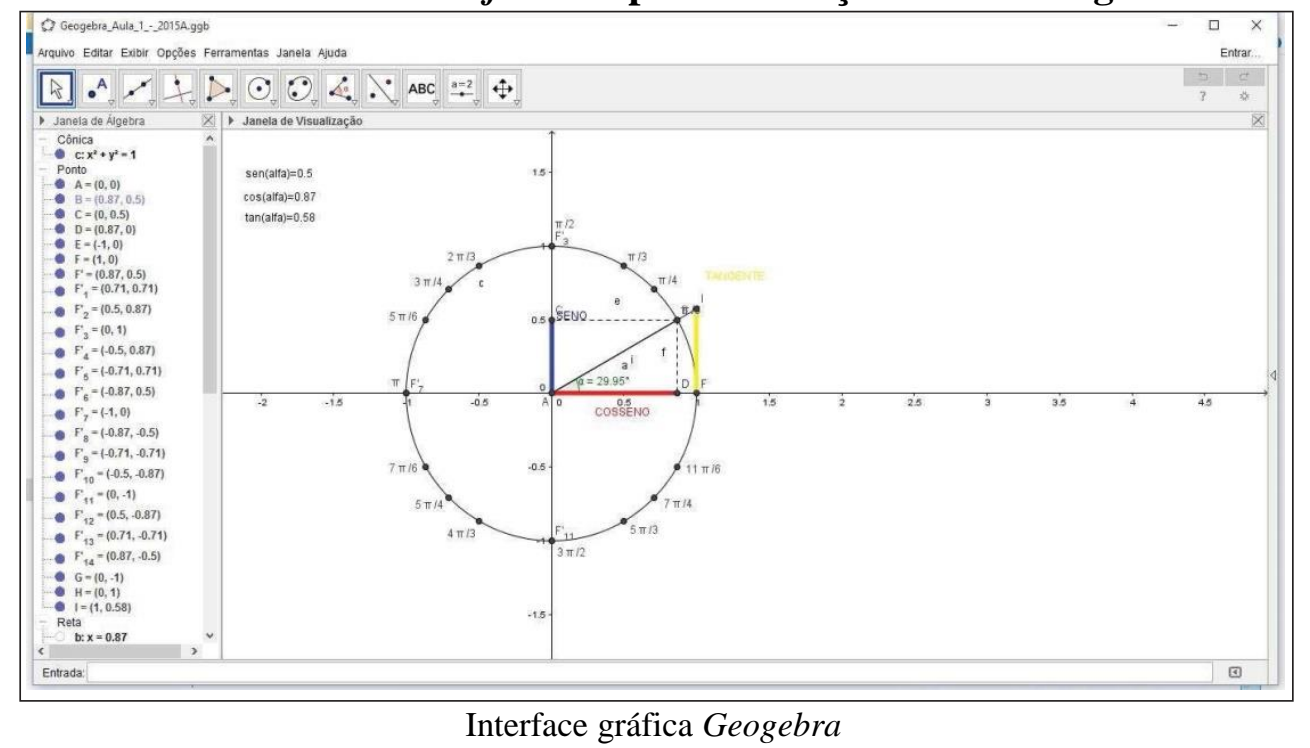

Reforçar, através de variados meios, a maneira como deveria ser conduzida a atividade tinha como pano de fundo fazer com que os alunos desenvolvessem-na com autonomia, motivação e compartilhamento de informações que viessem a ser percebidas como uma aprendizagem colaborativa. Além disso, tencionava-se que os alunos pudessem se sentir integrantes do processo ativo de construção do seu conhecimento. Na sequência, orientados pelo primeiro autor deste artigo, começaram a utilizar as funcionalidades da barra de ferramentas do software para construção do ciclo trigonométrico, bem como os gráficos das funções seno, cosseno e tangente.

No segundo período da aula 1, algumas atividades foram propostas, a exemplo das apresentadas no Quadro 1 apresentado a seguir. Tais atividades foram desenvolvidas com a mediação do uso do Geogebra, orientadas pelo primeiro autor deste artigo. A intenção de compartilhar informações e acompanhar o desenvolvimento da atividade individual ou em dupla foi relevante por proporcionar uma maior aproximação entre pesquisador e pesquisados. Ademais, abriu-se possibilidades para emersão de fatos não percebidos a priori quanto ao conhecimento que os alunos realmente tinham acerca do assunto, o que foi muito bom para que pudéssemos redimensionar as percepções iniciais e poder revisitar conceitos relacionados ao assunto que ainda não estavam claros para os alunos. 


\section{QUADRO 1 - Atividades propostas na aula 1}

Utilizando o ciclo trigonométrico que acabamos de construir no Geogebra, observe as relações existentes e desenvolva os exercícios a seguir.

1.ComoopontoBéumpontodoPlanoCartesianoedociclotrigonométrico,eleéumparordenado(x;y).Então: A medida do segmento $A C$, representado sobre o eixo $O y$, indica o(a) SENO do ponto B.

A medida do segmento $A \bar{D}$, representado sobre o eixo $O x$, indica o(a) COSSENO do ponto B.

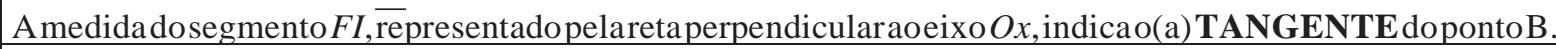

2. Utilize seu ciclo trigonométrico construído no Geogebra, para localizar os arcos e verifique os valores do seno, cosseno e tangente de cada ângulo.

\begin{tabular}{|c|c|c|c|c|c||}
\hline Ângulo / Função & 0 ou $0^{\circ}$ & $v / 2$ ou $90^{\circ}$ & v ou $180^{\circ}$ & $3 v / 2$ ou $280^{\circ}$ & $2 v$ ou $360^{\circ}$ \\
\hline Seno & & & & & \\
\hline Cosseno & & & & & \\
\hline Tangente & & & & & \\
\hline
\end{tabular}

3. Complete a tabela abaixo com os valores correspondentes para seno, cosseno e tangente para cada ângulo em graus, também transforme o valor de graus em radianos.

\begin{tabular}{|c|l|l|l|l|l|l|l|l|l|l|l|l|l|l|}
\hline $\begin{array}{c}\text { Ângulo } \\
\text { em graus }\end{array}$ & $30^{\circ}$ & $60^{\circ}$ & $90^{\circ}$ & $120^{\circ}$ & $150^{\circ}$ & $180^{\circ}$ & $210^{\circ}$ & $240^{\circ}$ & $270^{\circ}$ & $300^{\circ}$ & $330^{\circ}$ & $360^{\circ}$ & $420^{\circ}$ & $570^{\circ}$ \\
\hline $\begin{array}{c}\text { Ângulo em } \\
\text { rad. }\end{array}$ & & & & & & & & & & & & & & \\
\hline Seno & & & & & & & & & & & & & & \\
\hline Cosseno & & & & & & & & & & & & & \\
\hline Tangente & & & & & & & & & & & & & & \\
\hline
\end{tabular}

Escreva abaixo os pares de ângulos que têm o mesmo valor para o seno e para o cosseno.

a) Você consegue perceber alguma regularidade que ocorre entre os pares de ângulos com o mesmo valor para o seno e mesmo valor para o cosseno? Qual(is)?

b) Escreva abaixo os pares de ângulos que têm valores equivalentes opostos de seno e cosseno.

c) Você consegue perceber alguma regularidade que ocorre entre os pares de ângulos com valores equivalentes opostos de senos e cossenos? Qual(is)?

4. Observando a figura a seguir, retirada do ciclo trigonométrico que você acabou de construir, é possível observar um triângulo retângulo, que relaciona os valores de seno e cosseno.

a) Você consegue enxergar alguma relação conhecida?

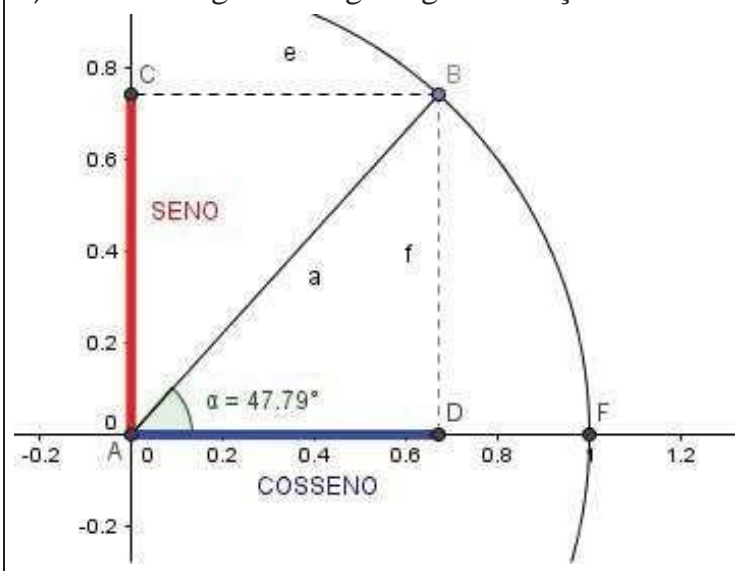

b) Explique seu pensamento matematicamente. 


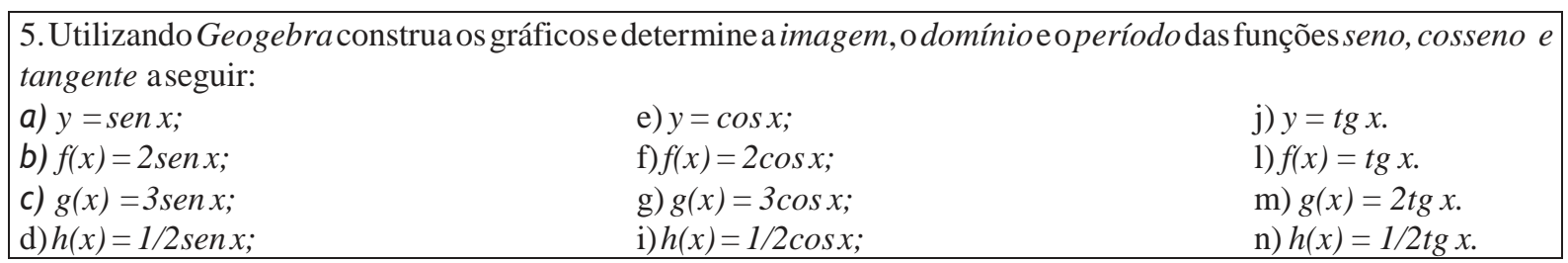

Fonte: os autores

As atividades propostas para reconstrução desses conceitos, esquecidos ou não aprendidos pelos alunos em séries/anos anteriores, tiveram o propósito de fazer a transição das razões trigonométricas no triângulo retângulo para o círculo trigonométrico de raio unitário. A utilização do software GeoGebra foi imprescindível para esse instante de transição. A percepção nos levou a crer em uma ocorrência de encadeamento das ideias que os alunos tinham acerca do assunto, ou seja, os alunos demonstraram estar utilizando conhecimentos anteriores ancorados cognitivamente, com o novo que estava sendo proposto, facilitando a construção da circunferência, visualizando relações e complementando conceitos ainda não consolidados em suas estruturas mentais.

Diante do resultado positivo apresentado no decorrer da atividade, pode-se dizer que a aprendizagem apresentou indícios de estar acontecendo significativamente, não apenas porque os alunos acertaram as questões propostas, mas porque conseguiram construir um conhecimento a partir da estratégia pedagógica da qual participaram. Tal conhecimento, por sua vez, servirá de base para novas conquistas cognitivas.

No seguimento, teve-se a preocupação de se apresentar triângulos internos às circunferências concêntricas com o objetivo de fazer com que os alunos reconhecessem os ângulos no círculo trigonométrico e fizessem a extensão das razões trigonométricas para ângulos maiores que $90^{\circ}$. Esperávamos que os alunos identificassem as razões trigonométricas como a projeção de um ponto no círculo trigonométrico de raio unitário. O desenvolvimento dessa atividade deu-se de forma tranquila, em que o objetivo específico foi alcançado. Procuramos também utilizar várias representações do círculo para que os alunos resgatassem os conhecimentos de representação fracionária em atividades que exigissem a definição de $\operatorname{arcos}$ em $\pi$ radianos. No decorrer da atividade, verificamos algumas dificuldades em utilizar as ferramentas do software, porém, nada que impedisse o desenvolvimento da mesma.

Ao término da aula 1, alguns alunos relataram que acharam a aula produtiva e demonstraram interesse em utilizar o Geogebra também em outras atividades, uma vez que o aplicativo oferece uma série de recursos que podem dinamizar os conteúdos e dar autonomia ao aluno, além de possibilitar a visualização em tempo real do ciclo.

$\mathrm{Na}$ segunda aula, os alunos foram instigados a construir os gráficos das funções seno e cosseno por meio do software Geogebra, utilizando os vários recursos que oferece. Para o aprofundamento, disponibilizamos a parte II do tutorial (MAMAN; ZIEGLER; PRITSCH, 2014) da construção do ciclo trigonométrico disponível no ambiente virtual dos alunos. Nesta aula, as atividades destinaram-se a determinar o seno, o cosseno e a tangente de um ângulo no círculo trigonométrico, por meio de projeções nos eixos das funções utilizando o software Geogebra. A atividade objetivou não só integrar de maneira definitiva o uso do computador como apoio à resolução de atividades, como também fazer com que os alunos fizessem conjecturas sobre ângulos complementares, suplementares e suas respectivas razões trigonométricas. Além disso, procuramos explorar e identificar as relações de simetria entre os ângulos de mesmas razões seno, cosseno ou tangente. 
Com intuito de problematizar um pouco mais o assunto, propôs-se que a realização dessa atividade fosse desenvolvida em duplas, pois nem todos os alunos da turma dispunham de um recurso computacional, notebook ou tablet, favorecendo, dessa forma, o envolvimento de todos. Sendo assim, foi possível fazer com que todos os alunos participassem do momento de construção e também da discussão das possíveis soluções das atividades propostas.

Durante a atividade, os alunos puderam comprovar algumas peculiaridades já explicitadas durante os questionamentos suscitados durante o processo de construção dos conceitos das funções em estudo. Constataram que, ao deslocar o gráfico da função seno em $\pi / 2$ unidades para a esquerda, obtém-se o gráfico da função cosseno. Faz-se saber que o processo de animação gráfica da função foi um dos pontos que mais chamou atenção dos alunos nesta atividade, fato demostrado através da (FIGURA 2).

\section{FIGURA 2 - Animação do ciclo trigonométrico}

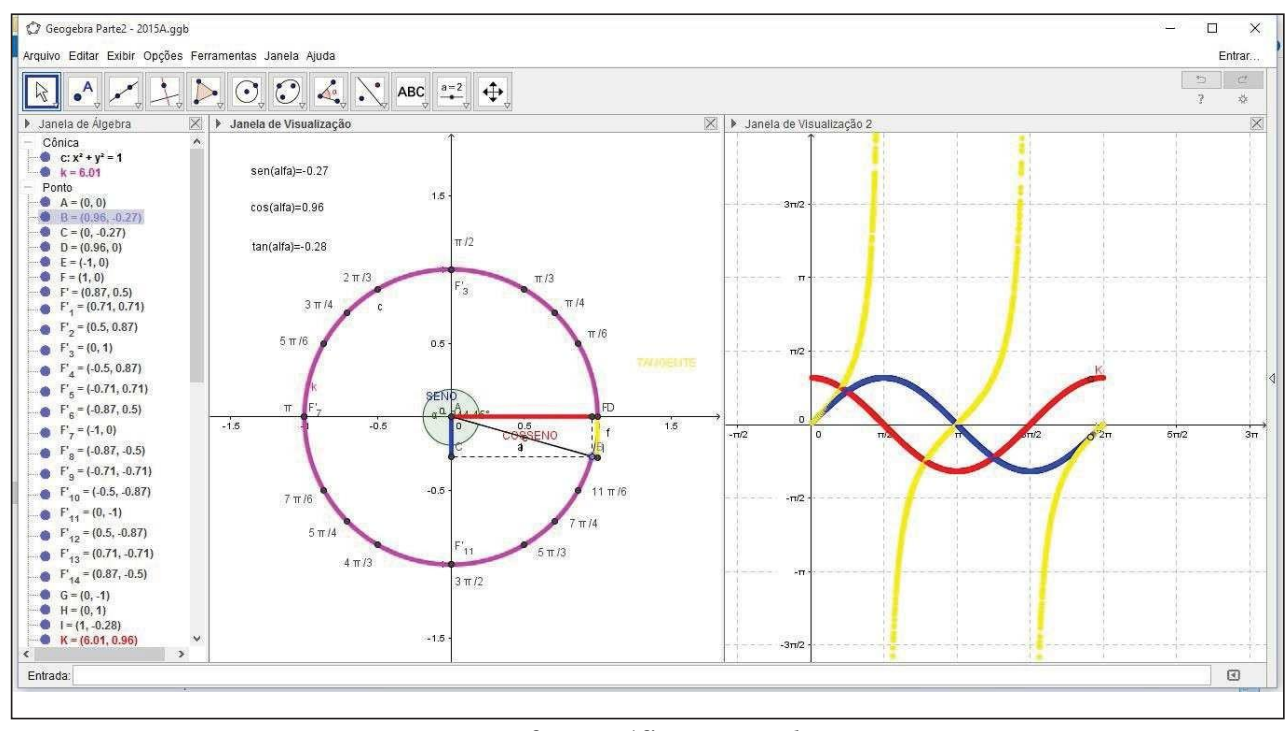

Interface gráfica Geogebra

O desempenho da leitura gráfica no software, na construção da segunda parte do ciclo trigonométrico para calcular as funções trigonométricas, foi o foco da atividade. Para reforçar, procuramos apresentar tarefas que preconizassem os arcos na representação em graus e também em radianos. A referida atividade objetivou sistematizar algumas razões trigonométricas obtidas por meios de fórmulas ou projeções.

Nesse conjunto de atividades, apresentamos o estudo da função seno. Inicialmente, os alunos deveriam conjecturar sobre como seria o gráfico da função $y=\operatorname{sen}(x)$. Para favorecer a compreensão das variáveis visuais (parâmetros da função) e as transformações do gráfico, antes de começar a representação gráfica, os alunos fizeram uma atividade no círculo trigonométrico no software com dois objetivos: familiarização com o software e verificação que, à medida que o ponto percorre a circunferência, os valores das funções seno, cosseno e tangente de seus respectivos gráficos se alteram. Nas atividades seguintes, os alunos observaram o comportamento do gráfico no software e reproduziram no papel para reforçar a observação e a compreensão dessa representação da função. A atividade encerrou-se com alguns questionamentos que serviram como sistematização dos conhecimentos abordados nas tarefas. 
As observações daquele momento nos levaram a acreditar que a atividade fora estimulante, desafiadora, instigante e causadora de reflexões por parte dos alunos identificadas em seus depoimentos, como, por exemplo: o fato do recurso animação ser determinante para o entendimento dos elementos período e frequência. Ainda nessa aula propomos atividades que ajudassem os alunos a manipular as ferramentas do software ao mesmo tempo em que o mesmo fosse utilizado para aprofundar os conceitos já discutidos. Dentre as atividades, apresentamos algumas, por exemplo, as citadas no Quadro 2:

\section{QUADRO 2 - Algumas atividades propostas na aula 2}

- Digite no Campo de entrada a função $f(x)=\operatorname{sen}(x)$

- Observe o gráfico e determine: o domínio $(\boldsymbol{D})$; imagem $(\boldsymbol{I m})$ e o período $(\boldsymbol{P})$.

- Construa os seletores $\boldsymbol{a}, \boldsymbol{b}, \boldsymbol{c}, \mathrm{e} \boldsymbol{d}$.

- Digite no campo de entrada a função $g(x)=a^{*} \operatorname{sen}(b * x+c)+d($ com $a$ e $b)$.

- Deixe os seletores $\mathrm{a}=1 ; \mathrm{b}=1 ; \mathrm{c}=0$ e $\mathrm{d}=0$ e movimente o seletor $\boldsymbol{a}$.

- Observando o gráfico determine, para este caso, o conjunto domínio, imagem e o período da função $g$.

- Verifique na janela algébrica e compare o gráfico das funções $y=\operatorname{sen}(x)$ e $y=-\operatorname{sen}(x)$.

O que o a faz na função?

- Deixe os seletores $\mathrm{a}=1 ; \mathrm{c}=0$ e $\mathrm{d}=0$ e movimente o seletor $\mathbf{b}$.

- Verifique na janela algébrica a função $g(x)$.

- Observando o gráfico determine o conjunto domínio, imagem e o período.

- Verifique: o que acontece quando aumenta ob? Equanto diminui o

b? O que o b faz na função?

- Deixe os seletores $\mathrm{a}=1 ; \mathrm{b}=1 ; \mathrm{d}=0$ e movimente o seletor $\mathbf{c}$.

- Verifique na janela algébrica a função $g(x)$.

- Observando o gráfico determine o conjunto domínio, imagem e o período de $g(x)$.

- Verifique: o que acontece quando aumenta o c? E quando

diminui? O que o c faz na função?

- Deixe os seletores $\mathrm{a}=1 ; \mathrm{b}=1 ; \mathrm{c}=0$ e movimente o seletor $\mathbf{d}$.

- Observe na janela algébrica a função $g(x)$.

- Observando o gráfico determine o conjunto domínio, imagem e o período da função $g(x)$.

- Verifique: o que acontece quando aumenta o d? E quando

diminui? O que o d faz na função?

$$
\text { Fonte: os autores }
$$

Utilizando o Geogebra e tomando como base as funções seno e cosseno, inerentes à atividade proposta, a construção gráfica das funções do tipo $f(x)=a+b \cdot \operatorname{sen}(c x+d)$ ou $g(x)=$ $a+b \cdot \cos (c x+d)$ tiveram como objetivo fazer com que os alunos pudessem interpretar os gráficos, a partir de suas representações na interface do software.

Borba, Silva e Gadanidis (2015) destacam que a possibilidade de que múltiplos gráficos possam ser gerados a partir do uso de softwares fazem com que as atividades de Matemática possam ser exploradas em diferentes contextos de ensino. Os autores consideram interessante o fato de que os alunos possam compreender a noção de funções "ao serem engajados em um cenário voltado à experimentação com tecnologias" (BORBA; SILVA; GADANIDIS, 2015, p. 27).

Em contraponto, Oliveira (2009) destaca que os softwares, elementos considerados essenciais à exploração de atividades matemáticas que carecem de abordagem diferenciadas, valendo-se, sobretudo, da visualização, são os elementos mais relevantes. Isto porque os programas, em si, não são elementos didáticos: 
[...] o termo software didático é meramente relativo, no máximo, a uma intenção, mas que sua efetividade didática depende de estratégia, planejamento, crítica, debate e significação. Não há software didático, por si, assim como não há tecnologias que educam (OLIVEIRA, 2009a, p. 6)

Para o autor, é preciso criar ambiências para que, no contexto de um trabalho que tenha por alvo construir conhecimentos e promover a autonomia dos estudantes, as tecnologias sejam mediadoras, auxiliando o professor em seu papel de orientação e promoção de interações. Para Oliveira (2009a, p. 4):

[...] os artefatos tecnológicos presentes nas situações didáticas podem ter um caráter mediador, permanecendo a serviço de uma estratégia didática que têm o aprendiz como foco, que busca entender e planejar de acordo com as mais diversas propostas que lhe permitam ampliar a autonomia diante do desafio de aprender.

De acordo com a sequência pensada para o conteúdo, propôs-se através de slides (animação no PowerPoint) que fossem feitas pelos próprios alunos, apresentações à turma sobre o comportamento do gráfico de determinada função do tipo $f(x)=a+b * \operatorname{sen}(c x+d)$ ou $g(x)=$ $a+b^{*} \cos (c x+d)$ a partir do que eles haviam construído, embasados pelo gráfico das funções elementares $f^{\prime}(x)=\operatorname{sen}(x)$ ou $g(x)=\cos (x)$. Com isso, almejou-se que percebessem as similitudes existentes entre estas. Destacou-se as relações de mudança dos períodos e imagens a partir da variação de seus coeficientes.

Com vista a pensar outra forma para representação de atividades similares, solicitou-se que as duplas construíssem os gráficos utilizando o papel e o lápis, por exemplo, das funções $f(x)=\operatorname{sen}(x)$ e $g(x)=3 * \operatorname{sen}(x)$. A partir das convicções de Borba, Silva e Gadanidis (2015), a natureza das representações e as possíveis formas de explorar conexões entre elas dependem da tecnologia utilizada. Os autores salientam que a mescla de tecnologias para explorar determinado assunto modificam a sala de aula e os ambientes educacionais, fomentando o aparecimento de ideias que ratifiquem o processo de aprendizagem implícito.

Nesta incursão, utilizando as tecnologias papel e lápis, caracterizadas como exploratórioinvestigativas, tiveram como objetivo principal a promoção e oferta de meios para o engajamento dos alunos frente às dificuldades enfrentadas para resolução de situações problema. Na sequência, foram convidados a fazerem no software. O primeiro passo foi digitar a função em voga na caixa de entrada (algébrica) do Geogebra, localizada na parte inferior esquerda da sua interface. Após confirmarem a escrita da função $f(x)=\operatorname{sen}(x)$ deram Enter e a senóide apareceu na grade gráfica.

O processo foi repetido para a função $g(x)=3 \operatorname{sen}(x)$. Na abordagem, levou-se em consideração a importância das comprovações visuais recorrentes ao que acontece com o gráfico quando se altera o parâmetro de $\mathrm{b}$ para um valor maior do que 1 e menor do que 1 . A ocorrência implica, consequentemente, em uma ampliação e compressão vertical do gráfico ao alternarmos os valores.

$\mathrm{Na}$ continuidade da atividade, solicitou-se que os alunos verificassem uma sequência de exercícios disponibilizados no ambiente virtual da disciplina. O objetivo foi a verificação de similitudes ou divergência entre as: $f(x)=\operatorname{sen}(x), g(x)=\cos (x), h(x)=3+4^{*} \cos (6 x-3)$ e t(x) $=-4 * \cos$. O feedback aos alunos foi que iniciassem o processo de representação gráfica a partir da função mais simples, incrementando os elementos pertinentes a cada uma delas de acordo com a necessidade. Ressalta-se que, no Geogebra, tem-se a possibilidade de omitir funções já escritas clicando sobre na aba representativa destas na janela algébrica. 
Nesta abordagem, foi trabalhado o domínio, o que nos propiciou um momento de considerações acerca da limitação da janela de visualização do Geogebra para períodos maiores. O design da atividade ofereceu meios para a exploração dos conceitos de limite, continuidade e derivada, realizando simulações, explorando recursos visuais do software. A intenção foi estabelecer conexões entre representações e objetos.

No primeiro período da aula 3, procurou-se fazer um resumo das atividades, quando se falou mais especificamente da função tangente. Os alunos foram organizados em duplas munidos de notebooks e, com o auxílio de um projetor multimídia, construíram-se e projetaramse os gráficos, simultaneamente aos dos alunos que, por sua vez, reproduziam o processo nos seus respectivos notebooks.

Diante do desenvolvimento do exercício exploratório, propusemos uma nova atividade, com o objetivo de oferecer condições ao aluno para que, partindo de situações práticas e com o auxílio do software Geogebra, conseguisse entender como também visualizar a aplicação dos fenômenos periódicos modelados matematicamente. Então, propôs-se uma atividade que partia de um tex to comum, porém com alterações de valores para cada dupla. Foi distribuída a situação conforme consta no (QUADRO 3).

\section{QUADRO 3 - Exemplo da problemática apresentada}

Em certo dia do ano, em uma cidade, a maré alta ocorreu à meia-noite. A altura da água no porto dessa cidade é uma função periódica, pois oscila regularmente entre maré alta e maré baixa, ou seja, a altura da maré aumenta até atingir um valor máximo (maré alta) e vai diminuindo até atingir um valor mínimo (maré baixa), para depois aumentar de novo até a maré alta, e assim por diante. A altura $y$, em metros, da maré, nesse dia, no porto da cidade, pode ser obtida, aproximadamente, pela fórmula: $y=2+1,9 \cdot \cos (\pi \cdot t / 6)$, sendo $t$ o tempo decorrido, em horas, após a meia noite. Esboçar o gráfico da função, determinando os respectivos períodos de tempo em que ocorre o menor e o maior nível da maré.

Adaptada da (Vunesp, 2010)

No intuito de dar maior consistência à abordagem de modelação, propôs-se aos alunos a construção do gráfico da função y com o auxílio do software. Esclareceu-se que deveriam seguir uma linha de raciocínio de forma que pudessem apresentar com clareza para os demais colegas o percurso tralhado para alcançarem o objeto proposto.

Diante do desafio, uma das duplas analisou o processo a partir de intervalos de tempo regulares, que consistiu na resolução da função e posterior representação gráfica para os instantes: $t=3 h ; t=6 h$ e $t=12 h$, desencadeando uma sequência gráfica representativa.

Solução para $t=3 h$ :

$$
\begin{array}{ll}
h(x)=2+1,9 \cdot \cos \pi t / 6 & h(x)=2+1,9 \cdot \cos 90^{\circ} \\
h(x)=2+1,9 \cdot \cos \pi / 2 & h(x)=2 m
\end{array}
$$

Para o instante $t=3 h$, os alunos encontraram inicialmente a solução através da resolução da equação proposta para a modelagem e, posteriormente, escreveram na caixa de entrada do software as duas funções designadas, chegando à conclusão de que, após três horas da chegada ao pico máximo, a maré tinha $2 m$ de altura. A seguir, apresenta-se a representação gráfica do instante $t=3 h$. 
FIGURA 3 - gráfico da função $f(x)=\cos \frac{\pi}{2} x$ e $h(x)=2+1,9 \cos (\pi / 2)$

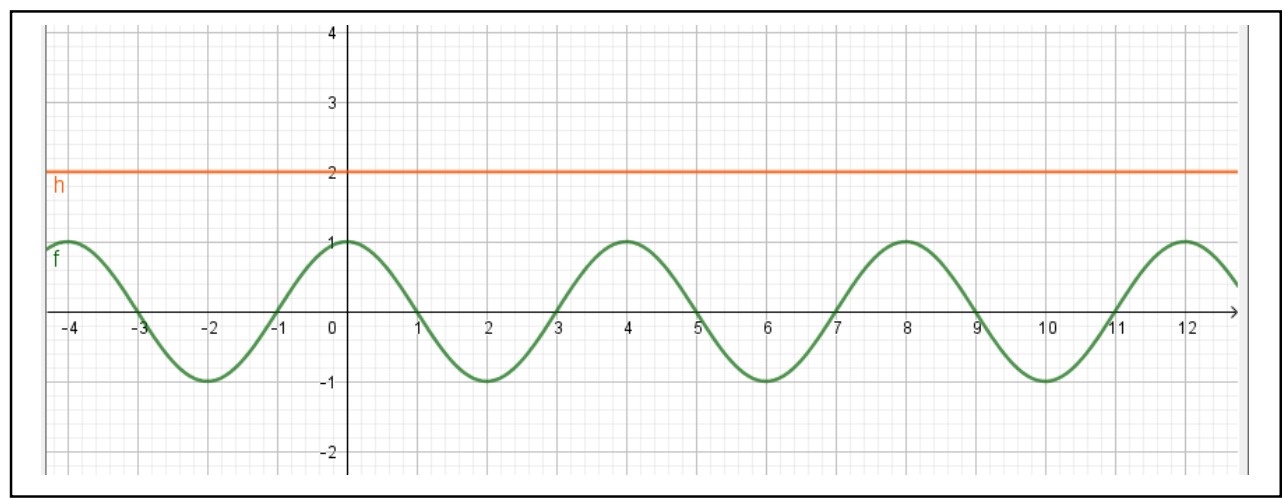

Fonte: os autores

Na sequência, repetiram o mesmo processo anterior repetindo agora a resolução da função para o instante, $t=6 \mathrm{~h}$ e, concluíram que, após transcorrido esse tempo, o nível da maré estava relacionado a $0,1 m$. No seguimento, demonstra-se o gráfico obtido a partir das funções $g$ e $m$.

FIGURA 4 - gráfico da função $g(x)=\cos (\pi)$ e $m(x)=2+1,9 \cos (\pi)$

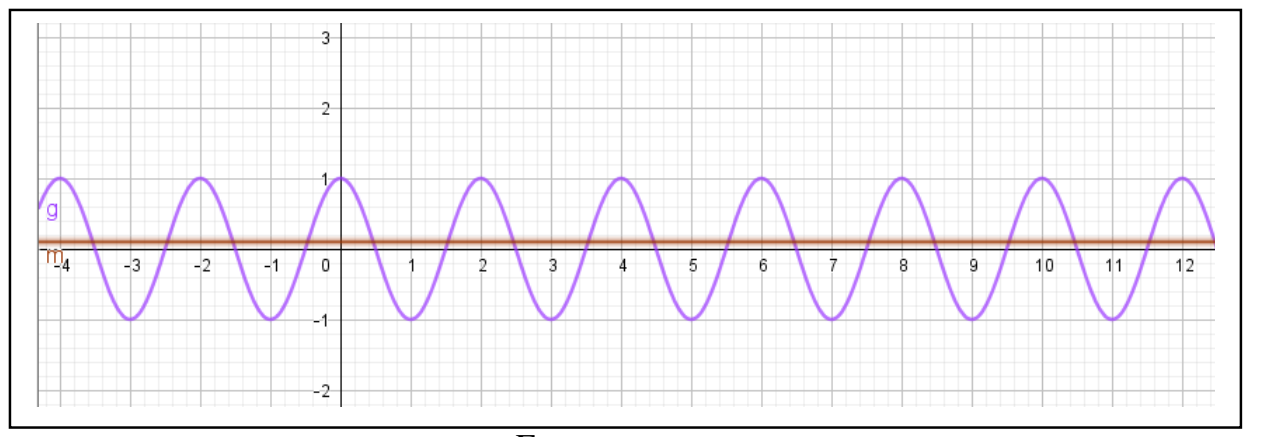

Fonte: os autores

No gráfico acima, temos a representação das dadas funções através da leitura do software Geogebra. Por ser um processo mecânico, omitimos de forma consciente a resolução algébrica da função implícita ao contexto.

No seguimento, a fim de concluírem a abordagem, esses alunos resolveram a equação para o instante $t=12 \mathrm{~h}$ e, posteriormente, representaram o intervalo de forma gráfica, escrevendo função na caixa de entrada do Geogebra. A intenção dos alunos foi de comprovar o resultado já obtido através da resolução algébrica da função, resultado que descreve a altura máxima atingida pela maré durante o período de $24 \mathrm{~h}$. 
FIGURA 5 - gráfico da função $k(x)=\cos (2 \pi)$ e $m(x)=2+1,9 \cos (2 \pi)$

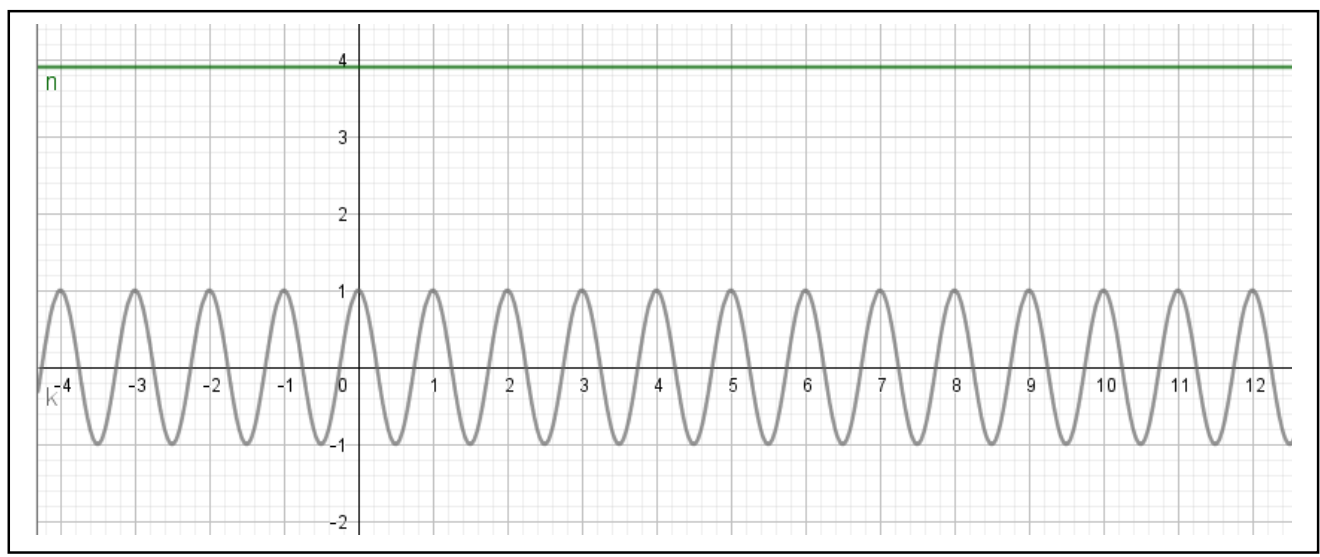

Fonte: os autores

Nesse, pode-se observar que a linha representava da função $n$ atinge o seu máximo em $3,9 \mathrm{~m}$. Dessa maneira, os alunos concluíram que os pontos de máximo e de mínimo, respectivamente, estavam relacionados aos instantes, $t=6 \mathrm{~h}$ e $t=12 \mathrm{~h}$.

Faz-se saber que outras abordagens com diferentes sequências foram apresentadas. Porém, todas com resultados convergentes, o que nos faz imaginar que a utilização de diferentes abordagens em sala de aula, pode propiciar possibilidades para que os alunos optassem por diferentes caminhos, mas que o objetivo comum foi atingido: a aprendizagem.

No último período da terceira aula, foi distribuída uma série de questões relacionadas às funções trigonométricas, além de uma questão avulsa para que fossem reconciliados os caminhos percorridos na modelagem da função apresentada. Para estas atividades, solicitou-se aos alunos que utilizassem somente o software para verificar o quanto tinham se apropriado da ferramenta.

A proposta teve como objetivo levantar questionamentos acerca dos benefícios de utilização do software Geogebra no contexto da disciplina. Também teve-se a intencionalidade de se refletir junto aos alunos os processos de ensino e de aprendizagem. Nesse sentido, procurou-se explorar ao máximo as questões relacionadas ao Quadro 4, apresentadas a seguir.

\section{QUADRO 4 - Atividade de verificação de aprendizagem da aula 3}

$$
\begin{aligned}
& \text { 1. Construir o gráfico de cada função trigonométrica, identificando o domínio, a imagem e o período: } \\
& \text { a) } y=y=1 / 2 \cos (x / 2) \\
& \text { b) } y=\cos x \\
& \text { c) } y=3 \cdot \operatorname{sen} 2 x \\
& \text { d) } y=1+2 \cdot \operatorname{sen}(\pi / 2-x) \\
& \text { e) } y=-1+\cos (x+\pi)
\end{aligned}
$$

2. Do solo, você observa um amigo numa roda gigante. A altura h em metros de seu em relação ao solo é dada pela expressão $h(t)=11,5+10 \operatorname{sen}[(v / 12) \cdot(t-26)]$, onde o tempo té dado em segundos e a medida angular em radianos.

a) Determine a altura em que seu amigo estava quando a roda começou a girar $(\mathrm{t}=2)$ ?

b) Determine as alturas mínima e máxima que seu amigo alcança e o gasto em uma volta completa.

c) Sem ter o gráfico da função dado pelo Geogebra, como você faria para calcular a altura do seu amigo?

Fonte: os autores 
Ao finalizar as atividades, ficou evidente a contribuição do software GeoGebra como uma ferramenta auxiliar no processo aos processos de ensino e de aprendizagem no conteúdo de trigonometria, pois com sua utilização, em cada uma das funções abordadas os alunos conseguiram realizar suas próprias interpretações e reflexões, baseando-se na construção e visualização dos gráficos encontrados. Todos esses atributos associados à explicação complementar discorrida pelo professor/investigador proporcionou uma atmosfera positiva entorno da retenção do conhecimento acerca dos elementos da trigonometria pelos alunos.

Ressalta-se, também, que a construção final desse material, assim como, a resolução destas e de outras atividades não contempladas na escrita deste trabalho, só foram possíveis, graças à presença do software que demonstrou ser um valioso recurso metodológico nos processos de ensino e de aprendizagem. Ademais, a utilização do recurso mostrou-se eficaz e profícuo quanto à apropriação dos conceitos básicos em situações que envolvem a trigonometria, especialmente por parte dos alunos.

\section{CONSIDERAÇÕES FINAIS}

Esse trabalho foi proposto com o objetivo de facilitar a compreensão de conceitos relacionados às funções trigonométricas, utilizando, para tanto, uma sequência de atividades desenvolvidas com o auxílio do software Geogebra. Assim, durante a realização das atividades, observamos o desempenho e o interesse dos alunos em realizar as atividades propostas no decorrer dos trabalhos. Para essa análise, consideramos o modo pelo qual eles resolveram as atividades, como manipularam o software utilizado, como também a interação entre os componentes da turma.

Como todo trabalho educacional, este também é fruto da inquietação do pesquisador em sua prática docente. Sendo assim, observou-se que o uso das TICs nas aulas de Matemática se converte num grande chamariz e promove maior compreensão do conteúdo quando o relacionamos com a análise e construção de gráficos das funções matemáticas. Conforme Braga (2010), Skovsmose (2000) e Allevato (2008), investigar a aprendizagem utilizando as TICs como ferramentas e seus impactos no aprendiz trazem reflexões preciosas à Educação Matemática; também trazem perspectivas diferentes na resolução de problemas e na consistência do trabalho colaborativo, estabelecendo um cenário de investigação, bem distinto da ideia de exercícios para a transmissão de algoritmos.

Durante a abordagem, procurou-se mesclar atividades que envolvessem problemáticas simples e problemas complexos, os quais tinham soluções diversas e, na busca pelas respostas, os alunos deveriam fazer a interpretação matemática, construir o gráfico e, a partir da sua análise, sustentar as soluções. Nesse sentido, supõe-se que a exploração do caráter visual, a combinação de raciocínios indutivo e intuitivo podem ter contribuído para que os alunos pesquisados pudessem desenvolver o seu raciocínio dedutivo quanto às similaridades das funções trigonométricas.

Percebeu-se, ainda, que o papel das diversas tecnologias usadas, mas, sobretudo a da tecnologia informática atribui um caráter experimental ao contexto em que foi desenvolvido o assunto, pois, com base em nossos objetivos, o design da atividade foi construído a partir dos recursos diferenciados por uma tecnologia que nos parece familiar à maioria dos alunos. As potencialidades do software com relação às variadas representações possíveis foram diretrizes 
no percurso da elaboração das atividades propostas, permitindo-nos explorar novas estratégias de abordagem do assunto, considerando o atual contexto educacional.

\section{REFERÊNCIAS}

ALLEVATO, N.S.G. O computador e a aprendizagem matemática: reflexões sob a perspectiva da resolução de problemas. In: Seminário em Resolução de Problemas, 1., 2008, Rio Claro/SP. Anais... Rio Claro/SP: I SERP, 2008.

BORBA, M de C. et al. Calculadoras Gráficas e Educação Matemática. Org: Estela Kaufman Fainguelernt e Franca Cohen Gottlieb. Rio de Janeiro: Art Bureau, 1999b.

BORBA, M de C.; SILVA, R. S. R. da; GADANIDIS, G. Fases das tecnologias digitais em Educação Matemática: sala de aula e internet em movimento. Belo Horizonte: Autêntica, 2015.

BORTOLI, G.; MARCHI, M. I.; GIONGO, I. M. Uma abordagem histórica no ensino da trigonometria. Curitiba, PR: Appris, 2016.

BRAGA, M. Concepções Acerca do Uso das TIC para Ensinar, Aprender e Construir Conhecimento Matemático Segundo uma Perspectiva Fenomenológica. 138 f. 2010.

Dissertação (Mestrado em Ensino de Ciências e Matemática) - Universidade Cruzeiro do Sul, São Paulo, 2010.

KALINKE, M. A. Tecnologias no Ensino: a linguagem matemática na web. Curitiba: CVR, 2014.

GEOGEBRA. Disponível em <www. geogebra.org>. Acesso em: jan. 2018.

MAMAN, A. S. de M.; ZIEGLER, J. de R.; PRISTSCH, R. A. Tutorial: Construção do Ciclo Trigonométrico e Funções. Disponível: os autores, 2015.

OLIVEIRA, Gerson P. Estratégias didáticas em educação matemática: as tecnologias de informação e comunicação como mediadoras. Anais do IV Simpósio Internacional de Pesquisa em Educação Matemática - IV Sipem. Brasilia: SBEM, 2009. 1 CD-ROM.

PROBLEMAS. Problemas de Trigonometria online. Disponível em: Vunesp, 2010. Acesso em jan. 2018.

SILVA, M. F. da; FROTA, M. C. R. Uma experiência com modelos da trigonometria associados a situações práticas. In: Encontro Nacional de Educação Matemática, X, 2010. Anais... Salvador.

SKOVSMOSE, O. Cenários para Investigação. Bolema, v. 13, n. 14, p. 66-91, 2000. 
SURVIO. Disponível em: 〈https://www.survio.com/survey/d/P9C9T9F8C3H9I7Y3C〉. Acesso em: jan. 2018.

VALENTE, J. A. O Computador na Sociedade do Conhecimento. Campinas, SP: Unicamp/Nied, 1999. 